\title{
Miscibility in Blends of Poly(2,6-dimethyl-1,4-phenylene ether) with Poly(styrene-co-methacrylic acid)
}

\author{
Isamu AKIBA, Yasushi OHBA, Yuka KoBorI, and Saburo AKIYAMA ${ }^{\dagger}$ \\ Department of Applied Chemistry, Faculty of Technology, \\ Tokyo University of Agriculture and Technology, \\ Koganei, Tokyo 184-8588, Japan
}

(Received October 27, 1999)

\begin{abstract}
In this study, miscibility between poly(2,6-dimethyl-1,4-phenylene ether), PPE, and poly(styrene-comethacrylic acid), P(S-co-MAA), is investigated by DSC, optical microscopy, and infrared spectroscopy. PPE is immiscible with $\mathrm{P}$ (S-co-MAA) when MAA content is higher than $7.2 \mathrm{~mol} \%$. The immiscibility seems to be caused by dimerization of MAA units.

KEY WORDS Miscibility / Polymer Blends / Interaction / Poly(2,6-dimethyl-1,4-phenylene ether) / Poly(styrene-co-methacrylic acid) /
\end{abstract}

It is well-known that miscibility and phase-separated structures have significant effects on performance of polymer blends. ${ }^{1,2}$ Therefore, controlling phase behavior in the polymer blends is of great importance for development of new polymer alloys. In the phase behavior in polymer blends, intermolecular interactions play important roles. ${ }^{1-3}$ Hence, many studies have focused on relationships between miscibility or phase-separated structure and intermolecular interactions in polymer blends. ${ }^{1-4}$

We studied the relationship between phase behavior and intermolecular interactions in strongly associating polymer blends. ${ }^{5-13}$ Miscibility enhancement and formation of network structures were found due to associative interactions between the components. However, when one component in polymer blends associates strongly with itself, it is expected that phase separation is induced. This study focuses on the miscibility in the polymer blends in which one component associates strongly with itself.

Poly(2,6-dimethyl-1,4-phenylene ether), PPE, is miscible with polystyrene, PS, in entire composition and temperature ranges. ${ }^{1,14}$ Carboxylic acids form associating dimers due to hydrogen bonds. ${ }^{3}$ We thus investigated the miscibility and interactions in $\mathrm{PPE} /$ poly(styrene-comethacrylic acid) (P(S-co-MAA)) blends.

\section{EXPERIMENTS}

\section{Materials}

PPE was supplied from Asahi Chemical Co., Ltd. PS and poly(styrene-co-methacrylic acid) with various contents of methacrylic acid unit, $\mathrm{P}(\mathrm{S}-\mathrm{co}-\mathrm{MAA})_{x}$, were supplied from Dainippon Ink Co., Ltd. Here, the subscript $x$ of $\mathrm{P}(\mathrm{S}-\mathrm{co}-\mathrm{MAA})_{x}$ represents MAA content in $\mathrm{P}(\mathrm{S}-\mathrm{co}-$ MAA) $(\operatorname{mol} \%)$. PPE, PS, and P(S-co-MAA) $)_{x}$ samples were used without further purification. The molecular characteristics of PPE, PS, and P(S-co-MAA $)_{x}$ are listed in Table I.

\footnotetext{
${ }^{t_{\text {To }}}$ whom correspondence should be addressed.
}

\section{Blend Preparation}

PPE and P(S-co-MAA $)_{x}$ at desired composition were dissolved in chloroform. The solution was mechanically stirred until became clear. The solvent was evaporated on glass plates at room temperature. The samples were dried at $80^{\circ} \mathrm{C}$ for 1 week and then for $150^{\circ} \mathrm{C}$ for $2 \mathrm{~h}$ at reduced pressure. The resulting samples were stored in a desiccator.

\section{Infrared Spectroscopy}

Infrared spectroscopy for PPE/P(S-co-MAA) $)_{x}$ blends was performed using JIR-WINSPEC35 Fourier transform infrared spectrometer, FT-IR. Blend samples were annealed at $230^{\circ} \mathrm{C}$ for $30 \mathrm{~min}$, granulated with $\mathrm{KBr}$ powder, and compression-molded to prepare pellets. All FTIR measurements were performed at a resolution of 2 $\mathrm{cm}^{-1} .100$ scans, at least, were signal averaged.

\section{Thermal Analysis}

Thermal analysis was carried using a Du Pont 910 differential scanning calorimeter, DSC. Samples were annealed at $230^{\circ} \mathrm{C}$ for $30 \mathrm{~min}$ and then quenched in liquid $\mathrm{N}_{2}$. All the DSC measurements were performed at a heating rate of $10 \mathrm{deg} \min ^{-1}$ under dry $\mathrm{N}_{2}$ atmosphere.

\section{Morphological Observation}

Morphology was observed using a Nikon S-Ke optical microscope equipped with heating stage. The morphological observation was performed at $230^{\circ} \mathrm{C}$.

Table I. Molecular characteristics of PPE, PS, and $\mathrm{P}(\mathrm{S}-c o-\mathrm{MAA})_{x}$

\begin{tabular}{|c|c|c|c|c|c|}
\hline Sample & $\frac{\text { MAA content }}{\mathrm{mol} \%}$ & $T_{\mathrm{g}} /{ }^{\circ} \mathrm{C}$ & $\bar{M}_{n} \times 10^{-4}$ & $\bar{M}_{w} \times 10^{-4}$ & $\bar{M}_{w} / \bar{M}_{n}$ \\
\hline PPE & & 212 & 2.3 & 5.1 & 2.2 \\
\hline PS & & 102 & & 37 & \\
\hline $\mathrm{P}(\mathrm{S}-c o-\mathrm{MAA})_{4.8}$ & 4.8 & 112 & 11 & 28 & 2.5 \\
\hline $\mathrm{P}(\mathrm{S}-\mathrm{co}-\mathrm{MAA})_{7.2}$ & 7.2 & 122 & 12 & 30 & 2.5 \\
\hline $\mathrm{P}(\mathrm{S}-\mathrm{co}-\mathrm{MAA})_{12}$ & 12 & 127 & 12 & 30 & 2.6 \\
\hline $\mathrm{P}(\mathrm{S}-\mathrm{co}-\mathrm{MAA})_{18}$ & 18 & 139 & 12 & 31 & 2.5 \\
\hline $\mathrm{P}(\mathrm{S}-\mathrm{co}-\mathrm{MAA})_{27}$ & 27 & 145 & 8.9 & 21 & 2.4 \\
\hline
\end{tabular}




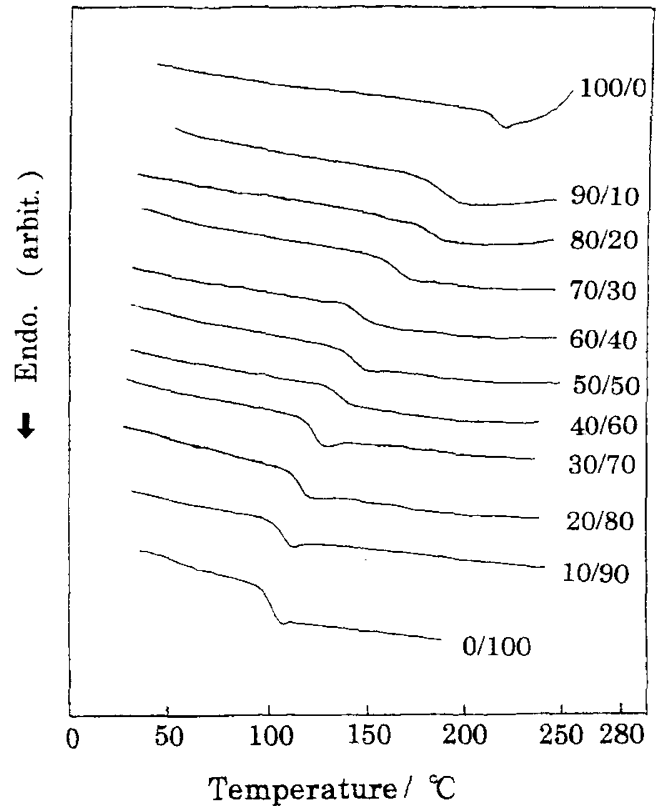

Figure 1. DSC thermograms for PPE/PS blends annealed at $230^{\circ} \mathrm{C}$.

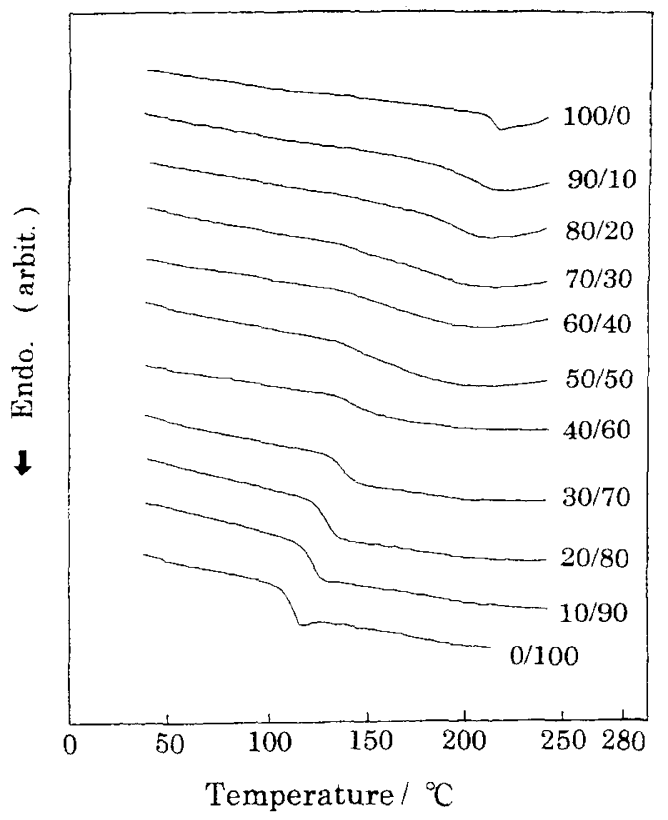

Figure 2. DSC thermograms for PPE/P(S-co-MAA $)_{4.8}$ blends annealed at $230^{\circ} \mathrm{C}$

\section{RESULTS AND DISCUSSION}

Figure 1 shows DSC thermograms for PPE/PS blends annealed at $230^{\circ} \mathrm{C}$. In the DSC thermograms of PPE/PS blends, single glass transitions were detected for all blend compositions. The single glass transition means that the polymer blend takes homogeneous single phase at annealing temperature. ${ }^{1,2}$ Therefore, it is suggested that PPE forms miscible polymer blends with PS, as indicated in the literatures. ${ }^{1,14}$ Figure 2 shows the DSC thermograms for PPE/P(S-co-MAA $)_{4.8}$ blends annealed at $230^{\circ} \mathrm{C}$. Single glass transitions are also detected for all

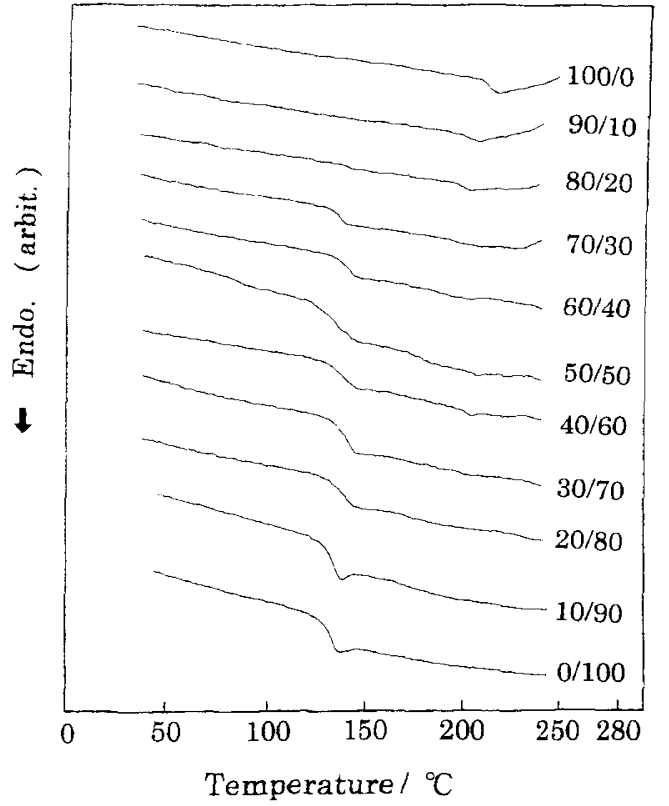

Figure 3. DSC thermograms for PPE/P(S-co-MAA $)_{27}$ blends annealed at $230^{\circ} \mathrm{C}$

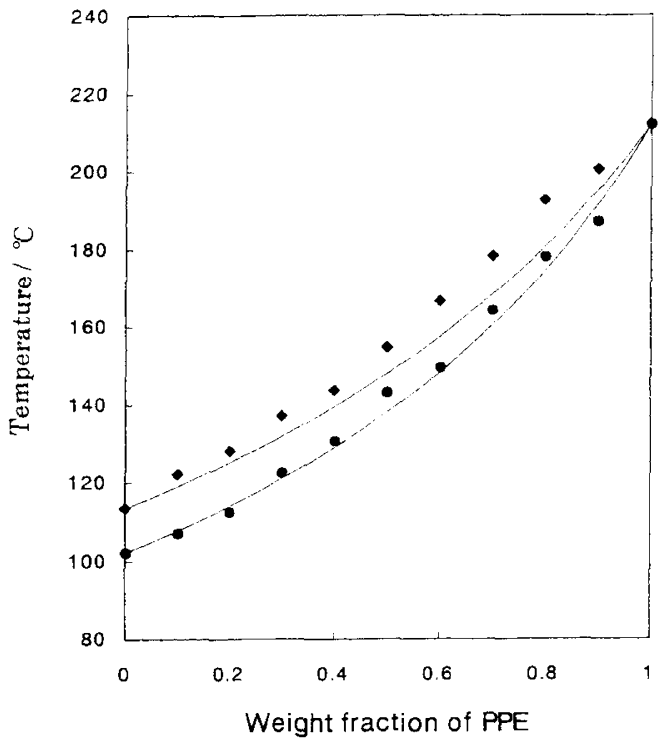

Figure 4. Plots of $T_{\mathrm{g}}$ against blend composition for PPE/PS and $\mathrm{PPE} / \mathrm{P}(\mathrm{S}-\mathrm{co}-\mathrm{MAA})_{27}$ blends annealed at $230^{\circ} \mathrm{C}:(\mathrm{O}) \mathrm{PPE} / \mathrm{PS}$ blends, (४) $\mathrm{PPE} / \mathrm{P}(\mathrm{S}-\mathrm{co}-\mathrm{MAA})_{27}$ blends.

blend compositions, suggesting the miscibility between $\mathrm{PE}$ and $\mathrm{P}(\mathrm{S}-\mathrm{co}-\mathrm{MAA})_{4.8}$ in entire blend composition at $230^{\circ} \mathrm{C}$. Figure 3 shows the DSC thermograms for the $\mathrm{PPE} / \mathrm{P}(\mathrm{S}-\mathrm{c} o \text {-MAA })_{18}$ blends annealed at $230^{\circ} \mathrm{C}$. In Figure 3 , two glass transitions are recognized in most blend compositions, suggesting the phase-separated states. Such two glass transitions were recognized in all DSC thermograms for the PPE/P(S-co-MAA $)_{x \geq 7.2}$ blends annealed at $230^{\circ} \mathrm{C}$.

Figure 4 shows plots of $T_{\mathrm{g}} \mathrm{s}$ of PPE/PS and PPE/P(S-co$\mathrm{MAA})_{4.8}$ blends versus weight fraction of PPE in the blends. $T_{\mathrm{g}}$ of PPE/PS and PPE/P(S-co-MAA $)_{4.8}$ blends are increasing systematically with weight fraction of 


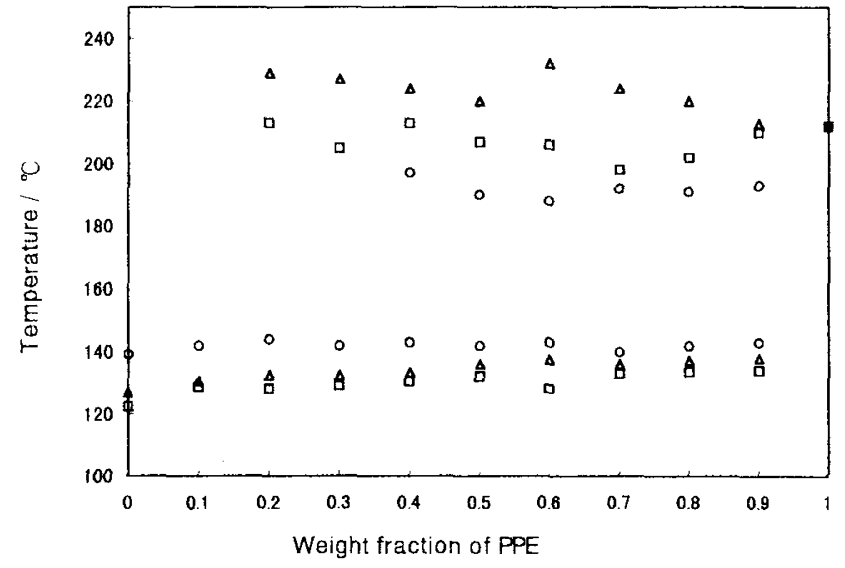

Figure 5. Plots of $T_{\mathrm{g}}$ against blend composition for PPE/P(S-coMAA) $)_{x}$ blends annealed at $230^{\circ} \mathrm{C}:(\square)$ PPE/P(S-co-MAA $)_{7.2}$ blends,

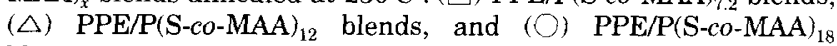
blends.

PPE. The composition dependence in the $T_{\mathrm{g}} \mathrm{s}$ for PPE/PS and $\mathrm{PPE} / \mathrm{P}(\mathrm{S}-\text { co-MAA })_{4.8}$ blends shows negative deviation from additive rules between $T_{\mathrm{gS}}$ of PPE and PS or P(S-co-MAA) ${ }_{4.8}$. This agree with general results for compositional dependence of $T_{\mathrm{g}} \mathrm{s}$ in the miscible polymer blends. Therefore, it is concluded that PPE is miscible with $\mathrm{P}(\mathrm{S}-c o-\mathrm{MAA})_{x \leqq 4.8} . T_{g} \mathrm{~s}$ of $\mathrm{PPE} / \mathrm{P}(\mathrm{S}-c o-\mathrm{MAA})_{x \geqq 7.2}$ blends, in which two glass transitions are observed in the DSC thermograms, are plotted against weight fraction of PPE in Figure 5. Two $T_{\mathrm{g}} \mathrm{s}$ of the PPE/P(S-co$\mathrm{MAA})_{x \geq 7.2}$ blends are almost invariable with variation of the blend composition and it seems that the two $T_{\mathrm{g}} \mathrm{s}$ correspond to those of PPE and $\mathrm{P}(\mathrm{S}-\mathrm{co}-\mathrm{MAA})_{x}$, respectively. $\mathrm{PPE}$ and $\mathrm{P}(\mathrm{S}-c o-\mathrm{MAA})_{x \geqq 7.2}$ are thus immiscible for almost all blend composition.

Figure 6 shows optical micrographs taken at $230^{\circ} \mathrm{C}$ for $\mathrm{PPE} / \mathrm{P}(\mathrm{S}-\mathrm{co}-\mathrm{MAA})_{4.8}$ and PPE/P(S-co-MAA $)_{7.2}=50 / 50$ $(\mathrm{w} / \mathrm{w})$ blends. As expected from DSC results, for PPE/P. $(\mathrm{S}-\mathrm{co}-\mathrm{MAA})_{4.8}=50 / 50(\mathrm{w} / \mathrm{w})$ blend any macroscopically heterogeneous structure is not seen, while PPE/P(S-coMAA $)_{7.2}=50 / 50(\mathrm{w} / \mathrm{w})$ blend shows heterogeneous structure. The blend seems immsicible with increasing $x$ of $\mathrm{P}(\mathrm{S}-\mathrm{co}-\mathrm{MAA})_{x}$. Associating dimerization of MAA units in $\mathrm{P}(\mathrm{S}-\mathrm{co}-\mathrm{MAA})$ or repulsive interactions between MAA units of P(S-co-MAA) and PPE may thus be unfavorable for miscibility. Carboxyl groups strongly associate with ether oxygen. ${ }^{3,12}$ Therefore, it is speculated that the phase separation in $\mathrm{PPE} / \mathrm{P}(\mathrm{S}-c o-\mathrm{MAA})_{x \geqq 7.2}$ blends is caused by associating dimerization of MAA units. However, dehydration between MAA units of P(S-co-MAA) may occur at $230^{\circ} \mathrm{C} .{ }^{15}$ The dehydration may induce phase separation. FT-IR measurements were performed to study interactions and reactions in the $\mathrm{PPE} / \mathrm{P}(\mathrm{S}-\mathrm{co}$ MAA) blends.

Figures 7 and 8 show FT-IR spectra for PPE/P(S-co$\mathrm{MAA}_{x}$ and PPE$/ \mathrm{P}(\mathrm{S}-\mathrm{co}-\mathrm{MAA})_{27}=50 / 50(\mathrm{w} / \mathrm{w})$ blends, respectively. All FT-IR spectra are taken for the annealed samples at $230^{\circ} \mathrm{C}$. The absorbance peaks centered at 1700 and $1730 \mathrm{~cm}^{-1}$ are assigned to carbonyl stretching in associating and free carboxyl groups, respectively. The associating carbonyls arise from associating dimerization of carboxyl groups. The formation of free carbonyls means the dissociation of the dimer of carboxylc acid.

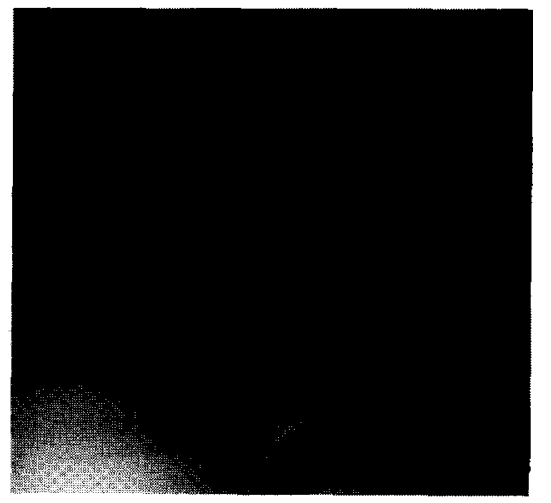

PPE $/ P(S-c o-M A A)_{4.8}=50 / 50(w / w)$

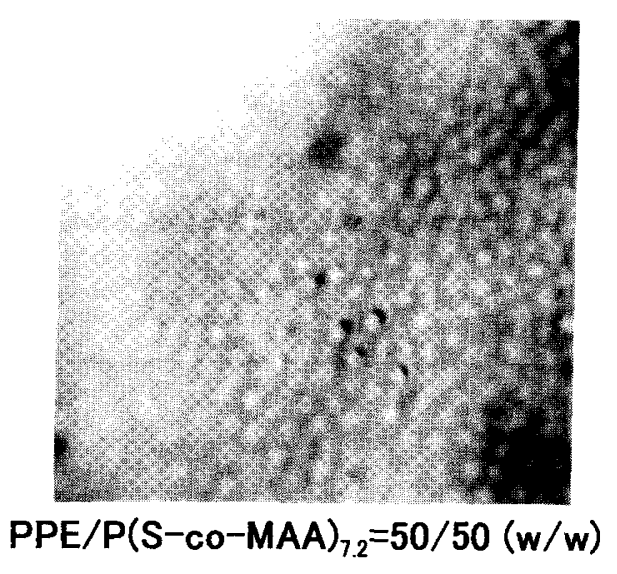

$10 \mu \mathrm{m}$

Figure 6. Optical micrographs for $\mathrm{PPE} / \mathrm{P}(\mathrm{S}-\mathrm{co}-\mathrm{MAA})_{4.8}$ and $\mathrm{PPE} /$ $\mathrm{P}(\mathrm{S}-\mathrm{co}-\mathrm{MAA})_{7.2}=50 / 50(\mathrm{w} / \mathrm{w})$ blends at $230^{\circ} \mathrm{C}$.

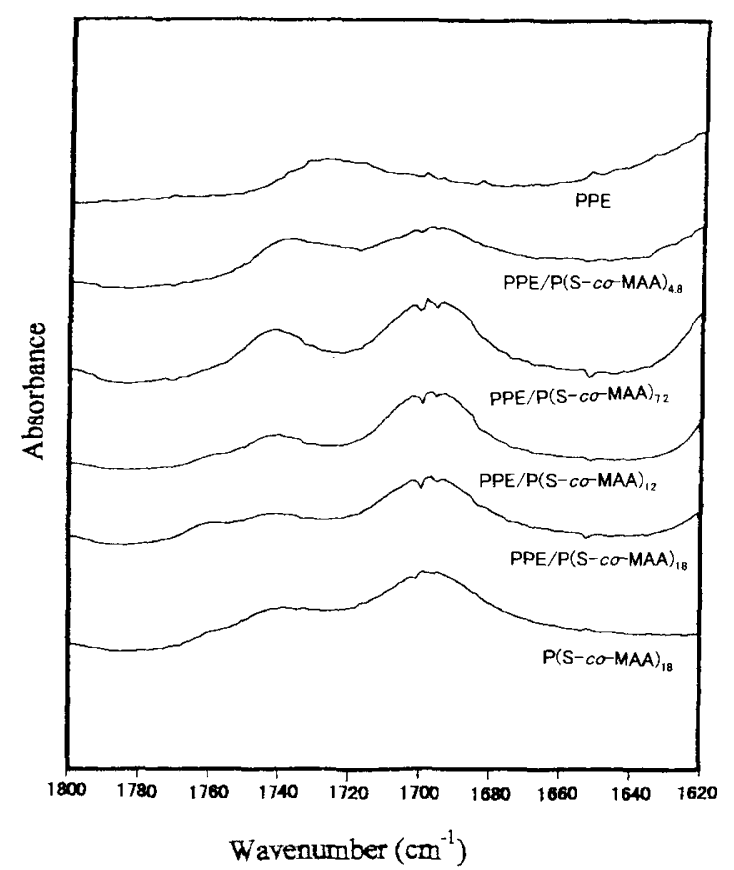

Figure 7. FT-IR spectra for PPE/P(S-co-MAA $)_{x}=50 / 50(\mathrm{w} / \mathrm{w})$ blends annealed at $230^{\circ} \mathrm{C}$. 


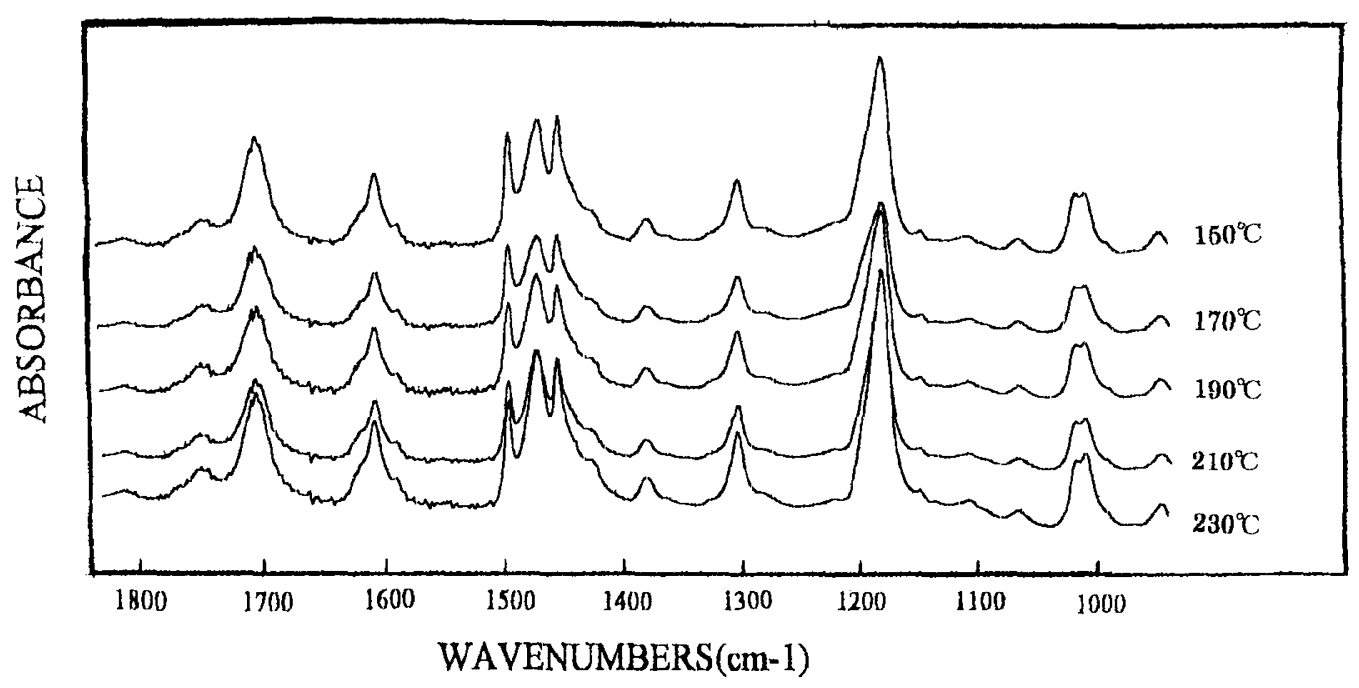

Figure 8. FT-IR spectra for PPE/P(S-co-MAA $)_{27}=50 / 50(\mathrm{w} / \mathrm{w})$ blends annealed at various temperatures.

In Figure 7, intensity of the absorbance of associating carbonyls increases with carbonyl group content in $\mathrm{P}(\mathrm{S}$ co-MAA $)_{x}, x$, compared with the intensity of the peaks of free carbonyl groups. The associating dimers of carboxyl groups thus increases with MAA content of $\mathrm{P}$ (S-co-MAA) in the PPE/P(S-co-MAA) blends. When dehydration between the carboxyl groups occurs, it is expected that a new peak centered at $1000 \mathrm{~cm}^{-1}$ should appear. ${ }^{15}$ However, as shown in Figure 8, no peak around $1000 \mathrm{~cm}^{-1}$ was recognized for any PPE/P(S-co-MAA $)_{27}=50 / 50(\mathrm{w} /$ w) blend. Therefore, it is considered that the dehydration does not occur at $230^{\circ} \mathrm{C}$. Thus, one may concluded that the immiscibility in PPE/P(S-co-MAA $)_{x \geq 7.2}$ blends is caused by the formation of associating dimers between MAA units of P(S-co-MAA).

Acknowledgment. The authors thank Dr. S. Kawahara of Nagaoka University of Science and Technology and Dr. S. Ichihara of Mitsubishi Chemical Co., Ltd. for helpful discussion.

\section{REFERENCES}

1. S. Akiyama, T. Inoue, and T. Nishi, "Polymer Blends-Compatibility and Interface", CMC R\&D Reports, Tokyo, 1979.

2. D. R. Paul and S. Newman, "Polymer Blends", Academic Press, New York, N.Y., 1978.

3. M. M. Coleman, J. F. Graf, and P. C. Painter, "Specific Interactions and the Miscibility of Polymer Blends", Technomic, Lancaster, 1991.

4. L. A. Utracki, "Polymer Alloys and Blends-Thermodynamic and Rheology--", Carl Hanser, Munich, 1989.

5. S. Akiyama, Bull. Chem. Soc. Jpn., 45, 1381 (1972).

6. S. Akiyama, N. Inaba, and R. Kaneko, Kobunshi Kagaku (in Japanese), 26, 529 (1969).

7. S. Akiyama and R. Kaneko, Kobunshi Ronbunshu (in Japanese), 31, 12 (1974).

8. S. Akiyama and R. Kaneko, Kobunshi Kagaku (in Japanese), 25, 145 (1968).

9. S. Akiyama, T. Nakatomi, and R. Kaneko, Kobunshi Kagaku (in Japanese), 29, 572 (1972).

10. S. Akiyama, Y. Komatsu, and R. Kaneko, Polym. J., 7, 2 (1975).

11. I. Akiba and S. Akiyama, Polym. J., 26, 873 (1994).

12. I. Akiba, Y. Ohba, and S. Akiyama, Macromolecules, 32, 1175 (1999).

13. S. Akiyama, K. Ishikawa, and H. Fujiishi, Polymer, 32, 1673 (1991)

14. P. R. Crouchman, Macromolecules, 11, 1156 (1978)

15. B. O. Ho, Y. D. Lee, and W. K. Chin, J. Polym. Sci., Polym. Chem. Ed., 30, 2389 (1992). 